\title{
Review of Energy Status and Associated Conservational Issues in Botswana
}

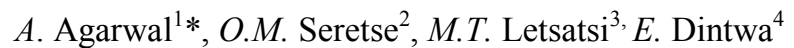 \\ 1,2,4 Department of Mechanical Engineering, University of Botswana, Gaborone. Botswana \\ ${ }^{3}$ Department of Industrial design and technology, University of Botswana, Gaborone. Botswana
}

\begin{abstract}
This paper discusses energy status of Botswana and the environmental concerns associated with the production of energy. It was offered in response to the growing concerns in industry about the need for the conservation of energy and for combating the increasing environmental degradation. Accomplishing vitality proficiency and diminishing ecological contamination are progressively essential parts of expert designing. The paper is meant to address top to bottom comprehension of basic issues of energy thrift and environmental consequences of irrational use of energy resources in industry. There is need for up to date technical knowledge and skills required for achieving the better management of energy, designing of energy-efficient systems and processes and the reduction and control of pollution cost-effectively. This information can successfully be coordinated to different segments of the economy for application and help the divisions in enhancing their aggressiveness despite lessening assets, likely considerable increment in unit vitality costs and the urgent requirement to comply with the increasingly-restrictive pollution-control standards.
\end{abstract}

\section{Introduction}

Energy is an essential element of modern societies. It is the forerunner for maintaining financial advancement and enhancing ways of life. Without a doubt present day vitality administrations are perceived as basic to enhance personal satisfaction and for supportable improvement as a rule. However the discerning and monetary utilization of vitality, with minimal harm to the earth is imperative for the future welfare of our planet. Providing energy for eradicating poverty has been a daunting task that has not been fully addressed. Efficient, affordable, adequate and reliable modern energy services are recognized as essential to improve quality of life and for sustainable development in general. The advancement of Botswana's economy is generally reliant on the abuse of assets, for example, minerals, water, vitality, natural assets, go assets and agrobiodiversity. Key financial parts, for example, tourism, mining, agribusiness are asset subordinate, while the employments of the lion's share, particularly in the country regions, are to a great extent gotten from characteristic assets. The accessibility and profitability of these assets, including woods, water, land and untamed life is vigorously affected by climatic conditions.[1] The digging division represents around 50 percent of the request, the business part around 20 percent, and the private segment around 25 percent. In the vicinity of 2004 and 2007 , country access to power multiplied to 44 percent, however shy of the 60 percent focus under the National Development Plan. The Government's "Vision" goes for 100 percent provincial access to help the more extensive advancement objectives of access to instruction and wellbeing, and in addition business openings, to the country and the burdened populace. The extending vitality emergency over the Southern Africa sub-area is a noteworthy hindrance to Botswana's monetary development designs, represents a risk to solidness, and requires a noteworthy deliberate exertion at the national and territorial levels to address the vitality challenge. Botswana, similar to a few different nations in the Southern Africa subregion, have up to this point depended on reasonable, plenteous, and solid power from South Africa.

\section{Status of Energy Sources in Botswana}

In 2008, Botswana imported around $2440 \mathrm{GWh}$ (67 percent of its energy necessities) from Eskom, the national electric utility of South Africa, while its own little 25-year-old coal control plant (Morupule A, $4 \mathrm{x}$ $33 \mathrm{MW}$ ) gave around 22 percent. The sub-locale, including outstandingly South Africa and different neighbors to Botswana, have been encountering extreme deficiencies of energy since the finish of 2007 because of high development and slacking interests in new limit. South Africa had begun stack shedding discontinuously since December 2007, a condition that is foreseen to compound through the medium term until the point when plentiful new age 
limit is fabricated and charged. Botswana is likewise encountering power outages and is thinking about load- Shedding because of its noteworthy reliance on Eskom, which has diminished its supply responsibilities from current levels to zero of every 2013 onwards under another business assertion. There is developing social and political weight in South Africa to stop fares to different nations.

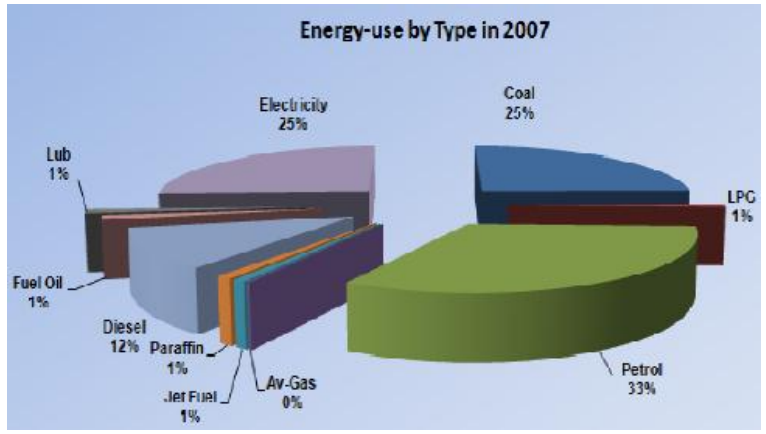

Fig. 1: A depiction of utilization in 2007 demonstrating the distinctive vitality sources, estimated in huge amounts of Oil Equivalent - TOE (Energy Affairs Department, 2007).

Figure 1 shows that, petrol is the most consumed energy source $(33 \%)$, followed by coal and electricity (25\% each), diesel (12\%) and other sources at about $1 \%$ each including solar. Energy security has developed as the significant national basic for the legislature of Botswana. There is profound worry in the legislature that the energy circumstance may prompt an emergency of certainty and political shakiness, which the nation can't manage. The administration's technique to react to the test is thorough, tending to the short-to medium-term and additionally long haul issues in vitality. The principle components of the administration's methodology are abridged under three subjects: (I) vitality security angles, including vitality preservation and proficiency, judicious improvement of local vitality assets, pulling in private part, and so on.; (ii) regular assets and protections perspectives to advance dependable utilize and way to deal with natural and social effects; and (iii) more extensive advancement viewpoints to address national, territorial, and worldwide concerns (e.g., environmental change).[2]

\subsection{Coal}

Botswana is endowed with a vast amount of coal resources. Investigations into the availability of coal deposits started prior to the independence of the country. It is currently known that coal deposits are well distributed along the eastern part of the country. The main coal deposits are located in Morupule, Moijabana Letlhakeng, Ncojane, Dukwi, Mmamantswe, Mmamabula, Serule, Dutlwe, Foley and Bobonong. Coal resources in these deposits are estimated to be in the region of 212 billion tonnes of which 3.34 billion tones are measured. Botswana coal is a low rank bituminous containing slate and shale. It is characterized by high ash, high sulphur, low caloric value, high friability and low volatile properties. Coal production commenced in 1973 at the Morupule coal deposit. Morupule colliery, which is the only coal mine in the country, is located $270 \mathrm{~km}$ north of the capital city, Gaborone. The mine is connected to the national railway line and the major road net-work for ease of coal distribution countrywide. Annual coal production at Morupule has steadily increased from 20,299 metric tons in 1973 to 921,000 metric tonnes in 1995/96.[3] In mid-1996 it dropped to 800000 metric tons due to the decommissioning of Selebi Phikwe power station and again there has been a steady increase to 928000 metric tons in 1998 and thereafter remained almost constant [4].

The mine has a production capacity of slightly over one million tonnes per annum. The urge for the country to have the security of coal supply for power generation, smelting of copper and nickel and of late, the production of soda ash at Sua-Pan has led to this steady increase in coal production. These major industrial sub-sectors of the economy consume close to $90 \%$ of the total production. In view of the abundant coal reserves, a study was conducted in 1984 with the assistance of Federal Republic of Germanys Technical Cooperation Agency (GTZ) with the purpose of investigating ways in which the use of coal could be broadened. One of the recommendations was the establishment of the Expanded Coal Utilization Project (ECUP), which was commissioned in 1987 with the overall objectives of: Reducing the depletion of the natural vegetation by relieving the use of fuel wood with coal where viable.

Reducing coal imports. Replacement of other energy sources like liquefied petroleum gas, where economically viable. To achieve these objectives, ECUP was charged with the responsibility of promoting coal utilization in industry, government institutions and households. ECUPs tasks also entailed the identification of coal using appliances that could burn on the locally produced coal safely, efficiently and in an environmentally friendly manner. The Project, through its mindfulness programs on the requirement for coal usage has empowered government foundations and ventures to set out on the utilization of coal for cooking, water warming and steam creation for various applications. Privately created coal is utilized as a part of the generation of meat items, material, cleanser, cowhide, blocks, and solid items, among others. Coal imports continue to flow into the country at a reduced level. 22,000 tonnes of coal were imported in 1981, while only 10,000 tonnes of coal were imported in 1994.[4] Due to the quality of Botswana coal, a beneficiation 
study has been undertaken that is geared at upgrading the quality of local coal to a level where coal imports could be substituted by locally produced coal. It is expected that the household sector would also benefit from the use of beneficiated coal briquettes which have less environmental hazards. Further Beneficiation or coal cleaning helps in the removal of inorganic sulphur. This is the cheapest way of reducing sulphur dioxide emissions.

\subsection{Electricity- The Botswana Power Corporation}

The bulk of the electricity used in Botswana is generated locally by the Botswana power Corporation (BPC). The rest is supplied by imports through cross border connections, the Department of Electrical and Mechanical Services (DEMS) and from private generation (generation by some industries for their own use).BPC is a parastatal under the Ministry of Mineral, Energy and Water Resources (MMEWR), was established in 1970. At its establishment, the national grid consisted of two parts, namely, the northern grid (electricity generation at Selibe Phikwe) and the southern grid (electricity generation in Gaborone). Prior to 1975 , only major urban towns were electrified. Major villages and small towns had their own power stations and internal reticulations. Examples of the latter include Palapye, Serowe and Mahalapye which were electrified in 1975 through SIDA financial assistance.In order to supply electricity beyond the above areas, the Morupule Power Station was constructed and commissioned in 1985. The total installed generation capacity is 132 MW. In addition, the northern and southern grid were connected to Morupule Power Station and the Gaborone Power station was later decommissioned. BPC operated both the Morupule and Selibe-Phikwe and the latter was decommissioned in 1996. The Selibe-Phikwe plant was coal fired and Morupule plant is also coal fired, the coal being availed by Morupule colliery. The total coal consumption of the two plants for the 1993/94 financial year was 603050 tonnes which was $69.6 \%$ of total production of the colliery [3]. The national grid is mostly concentrated along the railway line where the majority of the people live. Most of the major villages and a few other locations more than $100 \mathrm{~km}$ from the railway line have also been connected to the national grid. The national framework is relied upon to grow further to the remote regions with the presentation of Rural Electrification Program which plans to charge 14 towns consistently. The administration chose to quicken this program by charging 70 towns for a long time from September 1999 to September 2001. The BPC used to work various diesel-fuelled power control stations (called Central Power Supply Stations, (CPSS)) in areas which by prudence of their separation from the national lattice, were not yet associated. This wellspring of power contributed under $2 \%$ to yearly aggregate power supply[5].However due to Botswana government efforts of extending the grid to as many parts of the country as possible most of the locations have finally been connected to the grid. BPC has since decommissioned all the CPSSs in Botswana. The Department of Building and Engineering Services (DBES) of the Ministry of Works, Transport and Communication has installed diesel generators in public institutions/offices which are located in villages not connected to the grid. The total installed generation capacity amounts to approximately $20 \mathrm{MW}$ and contributes less than $2 \%$ of the total electricity supply [8].The generation facilities operated by DBES usually supply only one government institution. On average $70 \%$ of the total electricity supplied in Botswana is imported [8]. Imported electricity is mainly from South Africa and is supplied through $3 \mathrm{x}$ $132 \mathrm{KV}$ lines each of which has a $75 \mathrm{MW}$ gross capacity. There are also some cross border connections from Namibia which account for approximately $25 \mathrm{MW}$ gross capacity [8].

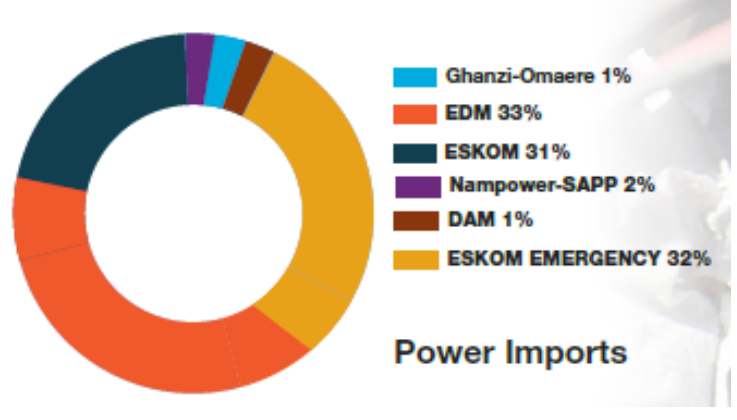

Fig. 2- Power import during 2015-16 [5]

Figure 2 shows the power imported during 2015-16. Hence the total electricity importation capacity from South Africa and Namibia has a firm capacity of 250MW. A further diversification of imported electricity supply to Botswana was achieved in 1991 through interconnection to Zambia by means of a 222 $\mathrm{kV}$ line. Although the use of this line is currently minimal, it is envisaged to provide $30 \mathrm{MW}$ of firm capacity in future. Botswana also has cross-border interconnections with Namibia. All interconnections are aimed at supplying electricity to remote villages adjacent to respective borders. Although most parts of Botswana have access to electricity, uptake of electricity varies greatly with settlement size and income group. In rural areas, small towns and low income areas of the larger settlements, connection rates are typically below 5\%. [5] Households in such locations generally find connection costs unaffordable. In urban areas electricity uptake is about $26 \%$. Overall, electricity uptake in Botswana is 
only about $10 \%$ of all the housing units due to high connection rates and tariffs [5].

On the demand side, Botswana's electricity sector shows a unique feature. Around $70 \%$ of its consumption are accounted for by only three consumers, i.e., the three largest mines (the Jwaneng and Orapa diamond mines and the copper-nickel mine -Bamangwato Concession Limited (BCL). This has an impact on BPCs overall load factor and also determines the peak load of the entire system. This could easily escalate into a big problem should one of these mines encounter some financial difficulties and close down. For example, the closing down of BCL which is currently subsidized by government and happens to be the leading consumer among the above three industries, could lead to the creation of excess capacity which would lower the gross profit margin of BPC and therefore create problems for both BPC and its other clients.

Botswana power get to achieved $71 \%$ of the populace in urban regions, while in rustic zones is as yet restricted to $24 \%$, albeit expanding. The national general power get to rate is $53 \%$. The Global Tracking Framework evaluates the national access to clean cooking arrangements at 62\%. Strategy destinations with respect to vitality get to are guaranteeing enhanced security of supply and unwavering quality of vitality supply to all parts of the economy. Government has set national power get to focus of $82 \%$ by 2016 and $100 \%$ by 2030 . Botswana depends mostly on power, coal, fuel wood and oil for its vitality requests. Add up to vitality supply for the nation in 2008 was 1604.10 toe with oil being the real provider took after by coal $(29 \%)$ and Electricity (17\%).

Sustainable power source assets for Botswana are sun powered, wind, and different types of bioenergy that incorporate biofuels and biomass squanders .Botswana has no enduring waterways and extensive dams and in this way has no potential for hydrocontrol. With respect to, Botswana has coordinate typical light (DNI) of $3000 \mathrm{kwh} / \mathrm{m} 2 /$ year, which is among the most noteworthy on the planet.

The region flanking Botswana, South Africa and Namibia is among the territories with the most astounding DNI. It is evaluated that utilizing under $1 \%$ of the nation territory, Botswana could meet its present power utilization. At a national level, a Rapid Assessment/Gap Analysis of the vitality area was delivered and following a demand dated January 2016, the nation will set out during the time spent building up its national SE4All Activity Agenda and Investment Prospectus with the specialized help of the SE4All Africa Hub.[6]

\subsection{Fuel-Wood}

While the resource potential, supply and demand figures of other energy sources are comparatively well documented, information on fuel-wood is fragmentary and insufficient for proper sub sector planning.

The total national growing stock of woody biomass has been estimated at 1400 million tonnes with an annual increment of 50 million tonnes. Regeneration capacity ranges from $0.3 \mathrm{t} / \mathrm{ha} /$ year to $2.1 \mathrm{t} / \mathrm{ha} /$ year and has a national average value of $0.93 \mathrm{t} / \mathrm{ha} /$ year.[7] Given an estimated standing stock density ranging from 3.6 tonnes/ha to 48.0 tonnes/ha, the regeneration rate is rather low. However, since the national fuelwood demand side was estimated at slightly over 1.6 million tonnes in the 1993 energy balance, the supply of fuel-wood is sustainable if proper policies regarding the harvesting of fuel-wood and which give due regard to sustainability of the environment are put in force. Fuel wood accounts for 48 percent of total energy used and almost 100 percent of domestic energy in rural areas[8].

Fuel-wood is mainly used for cooking, water heating, and space heating and in some cases, lighting. The methods, patterns and effect of fuel-wood harvesting and collecting vary according to location and the demand for various energy sources in the specific location. Although population growth within the context of dynamic economic growth would not lead to a worsening of the fuel-wood situation, it has led to the expansion of a poor underclass and to an increase in the rural-urban migration rate which in turn has exerted a constant increase in the demand for fuelwood.

Given the slow economic growth in rural areas, fuelwood will remain the staple fuel for many years to come unless programmes that will make alternative sources of energy both available and affordable to the population in the low and middle income group are put in place. Given that contribution to fuel-wood supply from afforestation is small (small scale plantation forestry initiated in the 1970s under the Rural Afforestation Programme has stagnated at $650 \mathrm{ha}$ ), the only solution to the unsustainable use of fuel-wood is inter fuel substitution. In urban areas and large villages, this will be a switch to paraffin, gas or electricity. The switch may be more difficult for the rural population which live in remote areas with neither the national grid nor proper distribution networks for the other fuels.

\subsection{New and Renewable Sources of Energy}

Renewable sources of energy can be defined as those sources that are inexhaustible. In Botswana these sources incorporate sun based, wind, bio-gas and to some degree, biomass vitality. With an end goal to expand the utilization of New and Renewable Sources of Energy which are right now utilized as a part of inconsequential sums, the Botswana government through applicable research foundations has done different exercises and pilot ventures. Nearby vitality assets thought to be in plenitude in Botswana 
incorporate coal (200 billion tons), daylight (3,200 hrs at $21 \mathrm{MJ} / \mathrm{m} 2)$, biogas $(2.2$ million steers, $3 \mathrm{~kg}$ excrement/LSU/day) and fuel wood (200 tons/annum).

\subsection{Solar Energy}

Botswana receives over 3200 hours of sunshine a year with completely cloudy days few and far between [9]. Average daily radiation on a horizontal surface is $21 \mathrm{MJ} / \mathrm{M} 2$. These conditions are favorable for solar energy applications. Currently solar energy is mainly used for water heating (mainly in urban areas), and lighting and refrigeration in homes, rural schools and clinics. Other applications, though on a very small scale, include solar desalination, telecommunications, signals in Botswana Railways, telemetry by North South Carrier, rural libraries, security lighting at cordon fence barrier gates and water pumping by Water Affairs etc. In 1992, as a pilot project, the Botswana government through Energy Affairs Division electrified 42 private houses and a clinic using solar energy. The purpose of the project was to assess the technical, social and economic viability of the system in a village environment.

The results of an evaluation carried out in 1994 showed that the installations provided tangible benefits to the community, are technically viable and socially acceptable to the users. The results and recommendation of the study led to the introduction of the National Photo-Voltaic Rural Electrification (NPVRE) scheme. This scheme was financed by the Government and its implementation was done through Rural Industries Innovation Centre (RIIC). The scheme was targeted at semi urban areas and villages. The main objectives of the scheme was to disburse loans at prime rate of interest to rural households for the purpose of installing PV lighting systems. Promote PV lighting systems of various sizes.

Strive to improve quality of life of the rural people. In order to promote good quality and safe installations the EAD together with local solar energy equipment suppliers developed guidelines for installation of domestic solar water-heating systems. The guidelines were used as a working document so as to, ensure that the installations provide value for money for those who buy the systems. To complement the guidelines, the EAD also offered on annual basis training on maintenance of solar water heaters to central government (DBES) and council employees who are responsible for maintenance of solar water heaters. The above effort together with more extension work, were intended to encourage increased use of technically and economically viable renewable energy technologies.

\subsection{Wind Energy}

The moderately low normal breeze speeds $(2-3 \mathrm{~m} / \mathrm{s})$ winning in Botswana confine wind vitality applications to water pumping. It is assessed that there are more than 200 windmills in activity, for the most part situated in the southern piece of the nation.

\subsection{Biogas}

Despite Botswana's relatively large cattle herd, the use of cow-dung to generate biogas has not taken off as initially expected. This is mainly because the grazing and animal husbandry practice used in the country of allowing the cattle to roam the veld looking for pastures is not conducive to efficient utilization of cow-dung as it (the dung) is deposited over wide areas, making its collection difficult.

\subsection{Petroleum products}

All of Botswana's petroleum requirements are imported in refined form, mainly from the Republic of South Africa (RSA) by local divisions of several international oil companies. Such companies include Shell Oil Botswana (Pty) Ltd, Total Botswana (Pty) Ltd B.P. Botswana (Pty) Ltd, Engen Botswana (Pty) Ltd, and Caltex Oil Botswana (Pty) Ltd. The Ministry of Mineral, Energy and Water Resources (MMEWR) through its Petroleum Management Unit (PMU) is responsible for monitoring of petroleum supply, pricing, contingency planning and management of strategic reserves. The actual procurement is carried out by the oil companies which also operate the strategic reserves under the supervision of the government. The real oil based commodities imported into the nation are recorded underneath: There are no known oil holds in Botswana.

\subsubsection{Petrol}

Petrol is the petroleum product most used by the final consumer. It is mainly used in the transport sector. Petrol is used to fuel equipment in other sectors e.g. Agriculture, construction, residential and government. Government regulates the prices of petrol by periodically fixing base prices. However, petrol prices differ from place to place due to transport cost.

\subsubsection{Diesel}

The contribution of diesel to the total amount of the petroleum products used in the economy comes second after petrol [1]. It is also mainly used in the transport sector, although substantial amounts of it are used for electricity generation and for operating equipment in the sectors indicated under petrol. Pricing system for diesel is similar to that of petrol.

\subsubsection{Paraffin}

Paraffin accounts for about $3 \%$ of all the petroleum products used [4]. It is mainly used in households for lighting. Its use as a cooking fuel is on the increase, and the trend is expected to continue as fuel wood scarcity increases. Pricing system for paraffin is similar to that of petrol and diesel. 


\subsubsection{Liquefied Petroleum Gas (LPG)}

LPG ranks fourth (after paraffin) in share of total petroleum imports[4]. LPG is mainly used for cooking and in a few cases for lighting as well. Its use is widely spread in the residential sector partly due to convenience and the high cost of electricity. The Government does not control LPG price. In addition to the oil companies, Botswana Oxygen and individual vendors also participate in the procurement and sale of LPG. As a result, its price varies widely even in one location.

\subsubsection{Fuel Oil, Aviation Gas and Jet Al}

Fuel oil is mainly used in industry while Aviation Gas and Jet A1 are used in the Aviation sub-sector. The contribution of the three fuels to total energy consumption is rising.

\section{Environmental Issues Associated with the Use of Energy Sources}

Nowadays issues of Environmental concern can neither be referred to as national or regional, they are a Global concern. The world's atmosphere is anticipated to change since human exercises are modifying the substance piece of the environment through the development of ozone depleting substances - essentially carbon dioxide, methane, and nitrogen oxides. The warmth catching property of these gases is undisputed. In spite of the fact that vulnerability exists about precisely how earth's atmosphere reacts to these gases, worldwide temperatures are rising. Vitality from the sun drives the world's climate and atmosphere, and warms the world's surface; thus, the earth emanates vitality once again into space. Air ozone depleting substances (water vapor, carbon dioxide and different gases) trap a portion of the active vitality; holding heat to some degree like the glass boards of a green house.

Without this regular nursery impact, temperatures would be much lower than they are currently, and life as known today would not be conceivable. Rather on account of ozone depleting substances, the world's normal temperature is a more affable $160 \mathrm{C}$. Likewise a gas like carbon dioxide is critical for living things that is vegetation and creatures. Trees require carbon dioxide for their photosynthesis procedure and thusly give oxygen to breath process in creatures. In any case, issues may emerge when the air centralization of ozone depleting substances increments.

\section{Why are greenhouse gas absorptions increasing?}

Researchers for the most part trust that the burning of petroleum derivatives and other human exercises are the essential purpose behind the expanded centralization of carbon dioxide. Plant breath and the decay of natural issue discharge in excess of 10 times the $\mathrm{CO} 2$ discharged by human exercises, yet these discharges have dependably been in adjust with the carbon dioxide consumed by plant photosynthesis.

\section{What has changed in the last couple of hundred years is the extra arrival of carbon dioxide by human exercises?}

Energy consumed to run autos and trucks, warm homes and organizations, and power manufacturing plants is in charge of around $80 \%$ of society's carbon dioxide discharges, around $25 \%$ methane outflows and around $20 \%$ of worldwide nitrous oxide emanations [9]. Expanded farming, deforestation, modern generation and mining additionally contribute a noteworthy offer of emanations.

\subsection{Environmental impact as a result of locally used fossil fuels}

Combustion of fossil fuels is a chemical process that results with its constituents which are elements and compounds, chemically combining with oxygen and each other to form a mixture of solids and gaseous compounds. The combustion products of a fossil fuel depends primarily upon:

a) The nature of the equipment that is used for its combustion process.

b) Constituents of the fuel.

c) The oxygen (air) that is made available for the process.

d) Proportional mixing of air and fuel (fuel-air ratio and Turbulence).

e) The time it takes for the process to complete.

f) The temperature at which the process takes place.

\subsubsection{Nitrous oxide and other nitrogen oxides (NOX)}

This is formed by a chemical combination of nitrogen and oxygen in the air for combustion. Atmospheric air contains only about $21 \%$ oxygen and about $70 \%$ nitrogen, the rest being other inert gases. Nitrogen is inert at temperatures below $1000{ }^{\circ} \mathrm{C}$, above this it does chemically react with oxygen to form a variety of oxides which are all toxic and not environment friendly. This is evident in all internal combustion (IC) as they burn fuel at very high temperatures to produce tremendous power at very high combustion efficiency.

\subsubsection{Ash}

This is an incombustible combustion residue material containing mineral compounds. It is the main constituent of Morupule coal at about 20\% [3]. Water vapour $(\mathrm{H} 2 \mathrm{O})$ - This is formed due to the chemical combination of Hydrogen $(\mathrm{H})$ in a fuel and oxygen for 
combustion.

\subsubsection{Fossil fuels, Combustion products}

Carbon dioxide (CO2) - This is an odorless, nontoxic and invisible gas. It is framed by the concoction mix of carbon and oxygen. It is an indication of good or finish ignition and assumes a noteworthy part in vegetation. Be that as it may it adds to a dangerous atmospheric deviation.

\subsubsection{Carbon monoxide (CO)}

This is an odorless, invisible and very toxic gas. It is formed by the chemical combination of carbon and less oxygen. It forms due to inadequate oxygen for a combustion process. It is a result of inefficient and incomplete combustion.

\subsubsection{Sulphur dioxide (SO2)}

This is a toxic smelly invisible gas formed by the chemical combination of sulphur (mainly in coal) and oxygen in the air for combustion. It depends on the sulphur content of the fuel. It can combine with, atmospheric water vapour to form acid rain and water vapour in flue gases to form light sulphuric acid which is very corrosive.

\subsubsection{Soot}

These are tiny micro particles of unburnt carbon. They are a sign of incomplete combustion and inefficient combustion process.

\subsubsection{Smog}

This is a combination of Hydrocarbons \{mainly Methane $(\mathrm{CH} 4)\}$ in a mixture form that escapes unburnt from a fuel. The escape normally happens at the initial ignition of a fuel. So far in Botswana there are a couple of segregated neighborhood natural effect related with the above items, because of the generation of vitality and other warm procedures like purifying of copper-nickel metal [9]. Further information on the emissions can be obtained from the Air Pollution Control section of the Department of Mines.

\subsection{Environmental impact as a result of fuel wood use locally}

Regions with low population density and high tree regrowth and woodland density (e.g. the north-western part of Botswana), have abundant availability of fuelwood. On the other hand, in areas of higher population density and low regeneration rates (e.g. eastern Botswana and around towns and large villages), evidence of localized over-exploitation can be seen easily. This problem is caused by the nonsustainable harvesting of fuel-wood for use as an energy source and for timber extraction, and by overgrazing and land clearing for agriculture development.

\subsection{Environmental impact as a result of electricity use locally}

Apart from being an end product of fossil fuels, invisible and silent killer, there are no known local environmental impacts associated with electricity. Environmental impacts as a result of new and renewable energy use locally. There are no known local impacts associated with the use of new and renewable sources of energy. In fact, these are the most save and environmentally friendly energy sources. The high cost of the technology is the one that hampers the local and worldwide use of it.

\section{Conclusion}

Global environmental issues are addressed yearly in different forums in different countries around the world. All of these are aimed at reducing the emissions of greenhouse gases and eradication of ozone depleting chemicals. Various conventions (Rio, Montreal, Kyoto and so on.), of which Botswana is gathering to, have been marked all went for worldwide ecological concern. Studies directed as of late, especially under the Intergovernmental Panel on Climate Change (IPCC), have examined the connection between ozone depleting substances and worldwide environmental change. An accord has developed, prescribing that such discharges should be lessened altogether worldwide to battle the risk of fast and genuine climatic change. Most as of late the reception of the Framework Convention on Climate Change (FCCC) built up that emanations of ozone harming substances ought to be constrained or diminished through an organized and purposeful universal exertion [6]. It is indispensable that countries should formulate energy climate change policies laden with incentives for renewable energy and fuel efficient technologies. This can benefit the environment and create a lot of jobs.

\section{References}

1. "Environment and Energy," 2017. [Online]. Available:

http://www.bw.undp.org/content/botswana/en/home /ourwork/environmentandenergy/overview.html. [Accessed: 25-Jan-2018].

2. "Botswana - energy sector overview." [Online]. Available:

http://www.mmegi.bw/index.php?sid=1\&aid=1253 \&dir=2012/June/Friday22/. [Accessed: 22-Jun2012].

3. "Morupule Colliery monthly data compilation, Ultimate and Proximate Analysis."

4. "Energy Statistical Bulleting," Energy affairs Division, Ministry of Minerals, Energy and Water resources. 
5. BPC, "Botswana Power Corporation Annual Reports."

6. "Botswana-At a glance." [Online]. Available: https://www.se4all-africa.org/se4all-inafrica/country-data/botswana/.

7. "Initial national Communication to the United nation Framework Convention on Climate Change."

8. M. Moyo, S.; O'Keefe, P.; Sill, The Southern African environment: profiles of the SADC countries. Earthscan Publications Ltd.

9. "Environmental Statistical Data,Central Statistics Office, Ministry of Finance and Development Planning," Gaborone, Botswana.

10. Energy Affairs Department. (2007). Energy Statistical Bulletin - 2007. Gaborone: Energy Affairs Department. 